\title{
Analysis of the critical success factors of automotive engine remanufacturing in India
}

\author{
Kaustov Chakraborty ${ }^{a *}$, Sandeep Mondal ${ }^{a}$ and Kampan Mukherjee ${ }^{b}$
}

${ }^{a}$ Department of Management Studies, Indian Institute of Technology (ISM), Dhanbad-826004, India ${ }^{b}$ Indian Institute of Management, Kashipur-244713, India

\begin{tabular}{l}
\hline C H R O N I C L E \\
\hline Article history: \\
Received July 2, 2016 \\
Received in revised format \\
September 10, 2016 \\
Accepted January 52017 \\
Available online \\
January 52017 \\
\hline Keywords: \\
Product recovery \\
Remanufacturing \\
Fuzzy TOPSIS
\end{tabular}

\section{Introduction}

Environmental awareness and increase in market demand for the new products have led to the development of new methods for reducing environmental pollution and effective consumption of natural resources by the industry. Extension of product's useful life through product recovery options can assist the company to achieve the above sustainability goals. Product recovery is a process where the remaining use value of the product is retrieved through several options such as reuse, repair, refurbishing, cannibalization and remanufacturing (Thierry et al., 1995). Among these options remanufacturing is considered as the most suitable option for automotive parts because of its better work content, quality and warranty (Ijomah et al., 2007). Remanufacturing is a process by which the used product is converted to 'as-new-as' the original product through several operations such as disassemble, cleaning, inspection and reassemble. Warranty of most of the remanufactured products is the same as the new product (Ijomah et al., 2007). Various researchers defined remanufacturing in their own ways. A remanufactured product requires only $50 \%$ of the manufacturing cost, $60 \%$ of the energy and $70 \%$ of the material than manufacturing of a new product (Govindan et al., 2015). These aforesaid benefits make automotive parts remanufacturing a popular and profitable business in developed

* Corresponding author

E-mail address: kaustovchakraborty8@gmail.com (K. Chakraborty)

(C) 2017 Growing Science Ltd. All rights reserved.

doi: $10.5267 / j . u s c m .2017 .1 .001$ 
countries like the United States and Europe. In the United States, the total amount of remanufactured product is increased by 15 percent from the year 2009 to 2011 and the value is close to $\$ 43.0$ billion (Sharma et al., 2014). Remanufacturing operation is highly profitable in automotive sector than any other sectors. A remanufactured automotive product/part can be a perfect ancillary of a new product/part because of the same quality and warranty compare to the new one and it reduces the GHG emission (Biswas \& Rosano, 2011). Developing countries like India and Brazil are still in the introductory phase to implement the remanufacturing process. According to Saavedra et al. (2013), only $11 \%$ of research on remanufacturing are carried out in Brazil and China, whereas the figure reaches about $80 \%$ in the United States and Europe. Till now, very few research studies have been carried out to identify the related issues of remanufacturing in India. Though some domestic companies in India already started remanufacturing operation (Mondal \& Mukherjee, 2009; Sharma et al., 2014) but the number is very less. The objective of this paper is to identify the barriers of automotive components remanufacturing in India and prioritize the critical success factors to overcome those barriers. To identify the critical success factor, fuzzy TOPSIS method is used. Two different fuzzy aggregation methods are used in this paper to analyse and compare the final priority ranking. Fuzzy logic is used with TOPSIS methodology to reveal the ambiguity and vagueness in the experts' opinion and degree of impact on the issues.

The structure of this paper is as follows. In section 2, a literature review is carried out. Section 3 consists of the brief illustration of the background of the company and along with barriers and the success factors, followed by the methodology in Section 4. Section 5 is related to the application of the approach and discussion with the managerial implication is in Section 6. Finally, the conclusion is in Section 7.

\section{Literature Review}

\subsection{Remanufacturing paradigm in developing countries}

In China, some research has been carried out in the area of remanufacturing in the automotive sector. Zhu et al. (2015) also discussed some strategic and operational barriers in truck remanufacturing in China. Tian et al. (2014) discussed on the requirement of the technological innovation for the development of automotive remanufacturing business in China. Technological innovation and upgradation are very much required in various steps in remanufacturing process. Abdulrahman et al. (2015) developed a strategic decision-making framework for remanufacturing. Xiang and Ming (2011) described how remanufacturing policies like Extended Producer Responsibility (EPR) help in the remanufacturing of automotive parts. A case study is done by $\mathrm{Du}$ and $\mathrm{Li}$ (2014) on the remanufacturing of the machine tool by OEM. In their paper, they described three types of industry based models (recycling, solution and trade in approach) in remanufacturing of machine tools. Wang et al. (2014) illustrated the influences of different subsidies in remanufacturing operations. Yusop et al. (2016) provided a clear picture of automotive remanufacturing in Malaysia in their paper. They conducted a survey based questionnaires among three group such as Government related agencies, Car manufacturers i.e. OEM and enforcement authorities. Shaharudin et al. (2015) identified some roadblocks in product returns and recovery in the manufacturing sectors of Malaysia. They identified that customers' performance and perception, economic and resource constraints are the major roadblocks which impede in product recovery. On the other hand, the remanufacturing scenario in India is still in infancy stage. An empirical study is done by Sharma et al. (2014) on the enablers and barriers in remanufacturing in the Indian context. They have identified competitive price is the major economic driver and lack of support from the government, quality related issues are the barriers in remanufacturing in India. Another case study is done by Govindan et al. (2016) on the automotive parts remanufacturing. They only keep their focus on the barriers in remanufacturing. Rathore et al. (2011) analysed the perception of the customers towards the remanufactured product and also analysed that whether remanufacturing operation is fruitful in the Indian context. Bhanot et al. (2017) developed a sustainability framework in manufacturing sector by identifying various enablers and barriers. They 
used DEMATEL method for developing the sustainability framework. Ravi (2015) developed an interactions model between the barriers to develop an eco-efficient packaging. Sabharwal and Garg (2013) evaluated the economic aspect of remanufacturing by using the graph theory approach. Various issues are analysed by Mukherjee and Mondal (2009) in photocopier remanufacturing in India. Saavedra et al. (2013) have done an exploratory case study on automotive remanufacturing in Brazil.

\subsection{Multi Criteria decision making in remanufacturing}

Feng et al. (2016) used Decision Making Trial and Evaluation Method (DEMATEL) technique to inspect the contribution of the remanufacturing sectors in their national economy and also investigated the energy saving and emission reduction aspects than other sectors. Govindan et al. (2016) developed a framework which address the interrelationships and interdependencies among the barriers in automotive remanufacturing in India. To address the interdependencies and inter relationships, they used Interpretive Structural Modeling (ISM) along with Analytic Network Process (ANP). Xia et al. (2015) developed a causal framework to analyse the internal barriers in automotive remanufacturing. For this purpose, they used Grey-DEMATEL method. Tian et al. (2014) used Analytic Hierarchy Process (AHP) to identify the main technological factors which are very much significant in development of automotive component remanufacturing in China. Zhu et al. (2015) developed a framework by using Grey-DEMATEL method to recognize the internal barriers in truck engine remanufacturing in china. Their study is focused only on strategic and operational dimensions. Jiang et al. (2011) used AHP in remanufacturing portfolio selection.

Golinska et al. (2015) developed a sustainability level for classification of the remanufacturing companies. For this classification, they used Grey Decision making method. Abdulrahman et al. (2015) identified the key elements for strategic decision making in remanufacturing. They used AHP method for identification the key elements. Bufardi et al. (2004) used multi criteria decision making tool to select the best EOL alternatives by using ELECTRE III method. They kept their focus on the selection of the best or the most suitable EOL alternative based on the users' preferences and environmental, economic and social performance. Rao and Padmanabhan (2010) used six attributes such as logistics cost, product cost, product value, total number of workers, emission of $\mathrm{SO}_{2}$ and $\mathrm{CO}_{2}$, recyclable cost, energy consumption etc. for analysing the best end of life scenario. They used fuzzy graph theory method to select the best scenario. Ghazalli and Murata (2011) developed an evaluation system for the end of life products by using the AHP and case based reasoning method. Chan (2008) developed a decision-making process to evaluate the optimal solutions from end of life options. They used Grey Relational Analysis (GRA) method for ranking the end of life options. Subramanian et al. (2014) used AHP method to rank the end of life reverse logistics factors in manufacturing sectors.

\section{Background of the company along with barriers and success factors}

The case study is carried out in a remanufacturing plant, situated in the western part of India, which is involved in remanufacturing of Midrange (MR), Heavyduty (HV) engine, long blocks (LB) and also different spare parts of automotive engines. Different industries like agriculture, oil and gas, mining, power generation, railway and marine are benefited from the service of their product. The used products or core are collected from its various distribution centers, followed by visual inspection and then transported to the warehouse. The remanufacturable cores are completely disassembled and thereafter cleaning (automatic cleaning and manual cleaning), crack detection, salvaging, reassembly and painting processes are done. The success factors which they have incorporated to overcome the barriers are listed in a tabular form, shown in Table 1. 


\section{Table 1}

Barriers and Success factors of remanufacturing in India

\section{Barriers}

Lack of remanufacturable product $(\mathrm{C} 1)$ : Products which are not designed for remanufacturing create problem while remanufacturing.

Uncertain quality and quantity of used products (C2): The quality and quantity of the used product sometimes are not good enough for remanufacturing.

Lack of proper design of reverse logistics network (C3): The Proper design of reverse logistics network makes remanufacturing profitable and effective.

Lack of proper database of the customers (C4): Proper database of the customers provides information about the used product.

Lack of Proper Legislative regulations (C5): Proper legislative law force the OEM to take proper action of their used product.

Lack of Advanced Remanufacturing Technology (C6): Advanced technology is necessary for remanufacturing.

Uncertainty in Supply and Demand (C7): Uncertainty in supply and demand make remanufacturing difficult.

Lack of Co-ordination between the actors in RSC (C8): Information sharing and coordination are important in reverse logistic.

Marketing related problem for remanufactured product (C9): Proper market of remanufactured product is an important issue in India.

Customer perception towards remanufacturing (C10): In India, customers have negative mindset towards the remanufactured product.

Uncertain Processing Time (C11): uncertain processing time is an intrinsic characteristic of remanufacturing.

Parts Mismatch problem (C12): Sometimes OEM avoid remanufacturing due to parts mismatch which may problem in the ownership of the product.

\section{Success factors}

Sustainable Product Design (A1) (Fang et al., 2014).

Proper Business Model (A2) (Sharma et al., 2014).

Technical Expertise (A3) (Mukherjee \& Mondal, 2009).

Company Policy (A4) (Sharma et al., 2014).

Proper Infrastructure \& Advanced Technology (A5) (Mukherjee \& Mondal, 2009, Experts).

Investment (A6) (Prakash \& Barua, 2015).

Support and Commitment from the Top Management (A7) (Prakash \& Barua, 2015).

Encouraged the customers to buy remanufactured products (A8) (Mondal \& Mukherjee, 2009).

Separate market for the new and remanufactured products (A9) (Mondal \& Mukherjee, 2009; Prakash \& Barua, 2015).

\section{Methodology}

In this paper, a case study approach is used to identify the barriers and critical success factors. The barriers and success factors are identified (shown in Table 1) from the literature review and from the experts' opinion of the remanufacturing company. The success factors are then prioritized by using Fuzzy TOPSIS method. Experts use linguistic terms to express the qualitative criteria. But, there are some vagueness, ambiguity and biasness in the expert's opinion. To eliminate the vagueness and biasness from the experts' opinion, fuzzy set theory is used. A fuzzy set (Zadeh, 1965) is defined by the membership function. Two different fuzzy aggregation method is used in this paper. The advantages of the TOPSIS method such as it's logical and rational nature, considers the distance from best and worst alternative, simple and easily programmable compel us to use Fuzzy TOPSIS in this 
paper. As we mentioned earlier, two different fuzzy aggregation method is used for priority ranking of the success factors which are described later and then the ranking is compared by the experts of the automotive engine remanufacturing plant.

Before going to describe the Fuzzy TOPSIS method in details, a few information related to fuzzy set theory is illustrated below. Triangular Fuzzy Number (TFN) is used by the experts to give fuzzy ratings of the alternatives and fuzzy relative importance weights of the criteria. TFN can easily handle those decision-making problems which contain both subjective and imprecise information. If $\tilde{X}=$ $\left(x_{1}, x_{2}, x_{3}\right)$ and $\tilde{Y}=\left(y_{1}, y_{2}, y_{3}\right)$, then following operation laws are follows:

$$
\begin{aligned}
& \tilde{X}+\tilde{Y}=\left(x_{1}+y_{1}, x_{2}+y_{2}, x_{3}+y_{3}\right) \\
& \tilde{X}-\tilde{Y}=\left(x_{1}-y_{3}, x_{2}-y_{2}, x_{3}-y_{1}\right) \\
& \tilde{X} * \tilde{Y}=\left(x_{1} y_{1}, x_{2} y_{2}, x_{3} y_{3}\right) \\
& \tilde{X} \div \tilde{Y}=\left(x_{1} / y_{3}, x_{2} / y_{2}, x_{3} / y_{1}\right)
\end{aligned}
$$

If $\tilde{X}=\left(x_{1}, x_{2}, x_{3}\right)$ and $\tilde{Y}=\left(y_{1}, y_{2}, y_{3}\right)$ are two TFN, then the distance between two TFNs are calculated by using vertex method, which is shown in Eq. (5).

$$
d(\tilde{X}, \tilde{Y})=\sqrt{\frac{1}{3} *\left[\left(x_{1}-y_{1}\right)^{2}+\left(x_{2}-y_{2}\right)^{2}+\left(x_{3}-y_{3}\right)^{2}\right]}
$$

A linguistic variable which is expressed in terms of linguistics terms and represented by TFN. In this paper, 0-1 scale is used to represent the relative weights of the criteria and 0-10 scale is used to represent the rating of the alternatives. The 0-1 and 0-10 scales (Kannan et al., 2014) are shown in Table 2 and 3 respectively.

Table 2

Linguistic variable and relative importance weight of the criteria

\begin{tabular}{cc}
\hline Linguistics & TFN \\
\hline No & $(0,0,0.2)$ \\
Very Low $(\mathrm{VL})$ & $(0,0.2,0.4)$ \\
Low $(\mathrm{L})$ & $(0.2,0.4,0.6)$ \\
Medium (M) & $(0.4,0.6,0.8)$ \\
High $(\mathrm{H})$ & $(0.6,0.8,1)$ \\
Very High $(\mathrm{VH})$ & $(0.8,1,1)$ \\
\hline
\end{tabular}

\section{Table 3}

Linguistic variable and relative rating of the alternatives.

\begin{tabular}{cc}
\hline Linguistics & TFN \\
\hline Very Poor (VP) & $(0,0,1)$ \\
Poor (P) & $(0,1,3)$ \\
Medium Poor (MP) & $(1,3,5)$ \\
Fair (F) & $(3,5,7)$ \\
Medium Good (MG) & $(5,7,9)$ \\
Good (G) & $(7,9,10)$ \\
Very Good $(\mathrm{VG})$ & $(9,10,10)$ \\
\hline
\end{tabular}

\subsection{Fuzzy TOPSIS 1}

In this Fuzzy TOPSIS 1 method, we use Graded Integration Method (GIM) to aggregate the experts' opinion related to criteria and alternatives (Kannan et al., 2009). 
A group of $\mathrm{E}$ decision makers $\left(D_{1}, D_{2}, \ldots \ldots, D_{E}\right)$ are used to construct a decision matrix which contains $\mathrm{M}$ numbers of alternatives $\left(A_{1}, A_{2}, \ldots, A_{M}\right)$ and $\mathrm{N}$ numbers of criteria $\left(C_{1}, C_{2}, \ldots, C_{N}\right)$. The decision matrix format is as:

$$
D=\left(\begin{array}{ccc}
p_{11} & \cdots & p_{1 N} \\
\vdots & \ddots & \vdots \\
p_{M 1} & \cdots & p_{M N}
\end{array}\right)
$$

Where, $p_{i j}$ is the rating of the $i^{t h}$ alternative with respect to the $j^{t h}$ criterion. Let $\left(W_{1}, W_{2}, \ldots ., W_{N}\right)$ are the relative weight vector of the criteria $\left(C_{1}, C_{2}, \ldots, C_{N}\right)$ respectively.

\section{Step 2: Aggregation of the decision-makers' individual evaluation}

Aggregation of the decision-makers' individual opinion towards the evaluation of the weights of the criteria and relative rating of the alternatives are calculated as: Suppose $w_{i e}=\left(x_{i e}, y_{i e}, k_{i e}\right), i=$ $1,2, \ldots, N \& e=1,2, \ldots, E$ be the assigned weight by the jth expert against the ith criteria. $w_{i e}=$ $\left(x_{i e}, y_{i e}, k_{i e}\right)$ is transformed into crisp number by using GIM. Consider $w_{i e}^{\prime}$ is the converted crisp number. Then the aggregated weight $w_{i}$ for the criteria $C_{i}$ is evaluated by using Eq. (6).

$$
w_{i}=\frac{\sum_{e=1}^{E} w_{i e}^{\prime}}{E}
$$

Similarly, for the aggregated rating of the alternatives, consider $p_{i j e}=\left(a_{i j e}, b_{i j e}, c_{i j e}\right), i=$ $1,2, \ldots, M ; j=1,2, \ldots, N \& e=1,2, \ldots, E$ be the assigned relative rating by the $e^{t h}$ expert against $i^{\text {th }}$ alternative and $j^{\text {th }}$ criteria. $p_{i j e}=\left(a_{i j e}, b_{i j e}, c_{i j e}\right)$ is transformed into crisp number by using GIM. Consider $p_{i j e}^{\prime}$ is the converted crisp number. Then the aggregated rating $p_{i j}$ for the alternative $A_{i}$ against the criteria $C_{j}$ is evaluated by using Eq. (7).

$$
p_{i j}=\frac{\sum_{e=1}^{E} p_{i j e}^{\prime}}{E}
$$

Step 3: Construction of the normalized matrix

The aggregated decision matrix of $\mathrm{M}$ alternatives and $\mathrm{N}$ criteria is normalized by using Eq. (8).

$$
S=\left[s_{i j}\right]_{m * n}
$$

where,

$$
s_{i j}=p_{i j} / \sqrt{\sum_{i=1}^{M}\left(p_{i j}\right)^{2}}
$$

Step 4: Construction of the weighted normalized matrix

The weighted normalized matrix is evaluated by multiplying the normalized matrix with the normalized aggregated weight of the criteria, which is shown in Eq. (9). The weighted normalized matrix is represented as $V=\left[v_{i j}\right]_{m * n}$. Where,

$$
v_{i j}=s_{i j} * w_{i}
$$


Step 5: Determination of positive and negative ideal solution

The evaluation of the positive and negative ideal solution is described in Eq. (10) and (11) respectively. The objective of Positive Ideal Solution (PIS)is to maximize the benefit criteria and minimize the cost criteria whereas the objective of Negative Ideal Solution (NIS) is just opposite to PIS.

$$
\begin{gathered}
A^{P}=\left\{v_{1}^{P}, v_{2}^{P}, \ldots, v_{n}^{P}\right\}, \text { where } v_{j}^{P}=\left\{\max \left(v_{i j}\right) \text { if } j \in(\text { benefit criteria }) ; \min \left(v_{i j}\right) \text { if } j\right. \\
\in(\text { cost criteria }) \\
A^{N}=\left\{v_{1}^{N}, v_{2}^{N}, \ldots, v_{n}^{N}\right\}, \text { where } v_{j}^{N}=\left\{\min \left(v_{i j}\right) \text { if } j \in(\text { benefit criteria }) ; \max \left(v_{i j}\right) \text { if } j\right. \\
\in(\text { cost criteria })
\end{gathered}
$$

Step 6: Distance calculation of each alternative from PIS and NIS

The distance of each alternative from PIS and NIS is calculated by using Eq. (12) and Eq. (13) respectively.

$$
\begin{aligned}
& d^{P}=\sqrt{\sum_{j=1}^{N}\left(v_{i j}-v_{j}^{P}\right)^{2}} \\
& d^{N}=\sqrt{\sum_{j=1}^{N}\left(v_{i j}-v_{j}^{N}\right)^{2}}
\end{aligned}
$$

Step 7: calculation of closeness coefficient and ranking of the alternatives

The closeness coefficient (CC) is evaluated by using Eq. (14). CC is used to rank the alternatives. The alternatives are ranked according to their CC value.

$$
C C_{i}=\frac{d^{N}}{\left(d^{P}+d^{N}\right)}
$$

\subsection{Fuzzy TOPSIS 2}

In this Fuzzy TOPSIS 2 method, instead of using GIM, the aggregation of the individual opinion of the decision-makers is done by Eq. (15) (Prakash \& Barua, 2015). Suppose the aggregating fuzzy rating $P=(a, b, c)$, then

$$
a=\min _{k}\left\{a_{k}\right\}, b=\frac{1}{k} \times \sum b_{k}, c=\max _{k}\left\{c_{k}\right\}
$$

Step 1: Development of decision matrix

Similarly, as the previous fuzzy TOPSIS method, A group of E decision makers $\left(D_{1}, D_{2}, \ldots \ldots, D_{E}\right)$ are used to construct a decision matrix which contains $\mathrm{M}$ numbers of alternatives $\left(A_{1}, A_{2}, \ldots, A_{M}\right)$ and $\mathrm{N}$ numbers of criteria $\left(C_{1}, C_{2}, \ldots, C_{N}\right)$. The decision matrix format is as:

$$
D=\left(\begin{array}{ccc}
p_{11} & \cdots & p_{1 N} \\
\vdots & \ddots & \vdots \\
p_{M 1} & \cdots & p_{M N}
\end{array}\right)
$$


where, $p_{i j}$ is the rating of the $j^{t h}$ alternatives with respect to the $i^{\text {th }}$ criterion. Let $\left(W_{1}, W_{2}, \ldots, W_{N}\right)$ are the relative weight vector of the criteria $\left(C_{1}, C_{2}, \ldots, C_{N}\right)$ respectively. Each decision maker use Table 3 to rating the alternative w.r.t the criteria. The aggregated fuzzy decision matrix is calculated by using Eq. (15).

Step 2: Normalization of the aggregated fuzzy decision matrix

The normalization procedure is done by using Eq. (16) and (17) respectively. Consider the aggregated fuzzy decision matrix is represented as $D=\left[p^{\prime}{ }_{i j}\right]_{m * n}$. For benefit criteria, the normalized value is

$$
p_{i j}^{\prime}=\left(\frac{a_{i j}}{c_{j}^{+}}, \frac{b_{i j}}{c_{j}^{+}}, \frac{c_{i j}}{c_{j}^{+}}\right), c_{j}^{+}=\max _{i}\left\{c_{i j}\right\}
$$

For the cost criteria, the normalized value is

$$
p^{\prime}{ }_{i j}=\left(\frac{a_{j}^{-}}{c_{i j}}, \frac{a_{j}^{-}}{b_{i j}}, \frac{a_{j}^{-}}{a_{i j}}\right), a_{j}^{-}=\min _{i}\left\{a_{i j}\right\}
$$

\section{Step 3: Construction of the weighted normalized matrix}

The weighted normalized matrix is evaluated by multiplying the normalized aggregated fuzzy matrix by the weights of the criteria, which is shown in Eq. (18)

$$
v_{i j}=p^{\prime}{ }_{i j} * w_{i}
$$

Step 4: Determination of positive ideal and negative ideal solution

PIS and NIS are calculated as discussed before in Fuzzy TOPSIS 1.

Step 5: Distance calculation of each alternative from PIS and NIS

The distance between PIS and NIS from each alternative is calculated by using Eq. (19) and (20) respectively.

$$
\begin{aligned}
& d_{i}^{P}=\sum_{j=1}^{N} d\left(v_{i j}, v_{i}^{P}\right) \forall i=1,2, \ldots, M \\
& d_{i}^{N}=\sum_{j=1}^{N} d\left(v_{i j}, v_{i}^{N}\right) \forall i=1,2, \ldots, M
\end{aligned}
$$

The value of $d\left(v_{i j}, v_{i}^{P}\right)$ and $d\left(v_{i j}, v_{i}^{N}\right)$ is calculated by Eq. (5)

Step 6: calculation of closeness coefficient and ranking of the alternatives

This step is same as the previous TOPSIS method. According the value of CC, we rank the alternatives.

\section{Application}

An expert team is formed which consists of five members. Out of five, three members are from the remanufacturing plant and the remaining two are academicians. All the experts have experience of more than seven years in their respective fields. Before data collection, the purpose of this study was thoroughly discussed with them. Then a structured interview was adopted for the data collection for developing the decision matrix. Experts use the linguistics terms from Table 2 and 3. 
Step 1: Development of decision matrix

The fuzzy decision matrix between alternatives w.r.t criteria is formed from the individual expert. Table 4 shows the fuzzy decision matrix of the second expert. Also, the individual assessment of the weight of each criterion is shown in Table 5.

Table 4

Fuzzy decision matrix of expert 2

\begin{tabular}{|c|c|c|c|c|c|c|c|c|c|c|c|c|}
\hline \multicolumn{13}{|c|}{ EXPERT 2} \\
\hline & C1 & $\mathrm{C} 2$ & C3 & C4 & C5 & C6 & C7 & C8 & C9 & $\mathrm{C10}$ & C11 & C12 \\
\hline A1 & VG & MG & $\mathrm{F}$ & MP & $\mathrm{F}$ & MP & MG & MP & $\mathrm{F}$ & MP & MP & $\mathrm{P}$ \\
\hline A2 & $\mathrm{F}$ & $\mathrm{G}$ & G & MG & $\mathrm{F}$ & MG & MG & VG & $\mathrm{F}$ & $\mathrm{F}$ & $\mathrm{F}$ & MP \\
\hline $\mathbf{A 3}$ & $\mathrm{P}$ & $\mathrm{P}$ & MP & $\mathrm{P}$ & $\mathrm{P}$ & $\mathrm{P}$ & $\mathrm{F}$ & $\mathrm{F}$ & MP & $\mathrm{F}$ & MG & MP \\
\hline A4 & G & $\mathrm{F}$ & $\mathrm{G}$ & G & G & MG & MP & F & MG & $\mathrm{F}$ & $\mathrm{P}$ & $\mathrm{P}$ \\
\hline A5 & VG & MP & G & G & MP & MG & MG & G & MG & F & G & G \\
\hline A6 & MG & MG & G & F & MP & G & MP & F & $\mathrm{F}$ & $P$ & $\mathrm{~F}$ & $\mathrm{P}$ \\
\hline A7 & $\mathrm{F}$ & $\mathrm{F}$ & $\mathrm{F}$ & G & $\mathrm{F}$ & MG & $\mathrm{F}$ & G & F & $P$ & MP & MP \\
\hline A8 & MP & $\mathrm{P}$ & MP & MP & MG & $\mathrm{P}$ & MP & MP & G & G & MP & $\mathrm{F}$ \\
\hline A9 & $\mathrm{F}$ & $\mathrm{F}$ & G & $\mathrm{F}$ & G & MP & G & MP & VG & VG & MP & $\mathrm{P}$ \\
\hline
\end{tabular}

Table 5

Individual assessment of the weight of each criterion

\begin{tabular}{llllll}
\hline & D1 & D2 & D3 & D4 & D5 \\
\hline C1 & $\mathrm{H}$ & $\mathrm{M}$ & $\mathrm{VH}$ & $\mathrm{H}$ & $\mathrm{M}$ \\
C2 & $\mathrm{VH}$ & $\mathrm{H}$ & $\mathrm{M}$ & $\mathrm{H}$ & $\mathrm{H}$ \\
C3 & $\mathrm{H}$ & $\mathrm{H}$ & $\mathrm{H}$ & $\mathrm{M}$ & $\mathrm{M}$ \\
C4 & $\mathrm{M}$ & $\mathrm{M}$ & $\mathrm{H}$ & $\mathrm{M}$ & $\mathrm{M}$ \\
C5 & $\mathrm{H}$ & $\mathrm{M}$ & $\mathrm{H}$ & $\mathrm{H}$ & $\mathrm{H}$ \\
C6 & $\mathrm{H}$ & $\mathrm{M}$ & $\mathrm{VH}$ & $\mathrm{L}$ & $\mathrm{M}$ \\
C7 & $\mathrm{M}$ & $\mathrm{H}$ & $\mathrm{M}$ & $\mathrm{VH}$ & $\mathrm{M}$ \\
C8 & $\mathrm{H}$ & $\mathrm{M}$ & $\mathrm{M}$ & $\mathrm{L}$ & $\mathrm{M}$ \\
C9 & $\mathrm{H}$ & $\mathrm{H}$ & $\mathrm{VH}$ & $\mathrm{H}$ & $\mathrm{VH}$ \\
C10 & $\mathrm{M}$ & $\mathrm{H}$ & $\mathrm{M}$ & $\mathrm{H}$ & $\mathrm{M}$ \\
C11 & $\mathrm{L}$ & $\mathrm{L}$ & $\mathrm{M}$ & $\mathrm{H}$ & $\mathrm{M}$ \\
C12 & $\mathrm{L}$ & $\mathrm{M}$ & $\mathrm{L}$ & $\mathrm{L}$ & $\mathrm{M}$ \\
\hline
\end{tabular}

Step 2: Aggregation of the decision-makers' individual evaluation

The individual expert's opinion for fuzzy rating matrix of the alternative and the weight of each criterion are aggregated.

Table 6

Aggregated weight of each criterion in Fuzzy TOPSIS 1

\begin{tabular}{|c|c|c|c|c|c|c|}
\hline & D1 & D2 & D3 & D4 & D5 & WEIGHT $\left(\mathbf{W}_{\mathrm{i}}\right)$ \\
\hline C1 & $\mathrm{H}$ & $\mathrm{M}$ & $\mathrm{VH}$ & $\mathrm{H}$ & $\mathrm{M}$ & 0.7532 \\
\hline $\mathrm{C} 2$ & $\mathrm{VH}$ & $\mathrm{H}$ & M & $\mathrm{H}$ & $\mathrm{H}$ & 0.7932 \\
\hline C3 & $\mathrm{H}$ & $\mathrm{H}$ & $\mathrm{H}$ & M & M & 0.72 \\
\hline C4 & M & M & $\mathrm{H}$ & M & M & 0.64 \\
\hline C5 & $\mathrm{H}$ & M & $\mathrm{H}$ & $\mathrm{H}$ & $\mathrm{H}$ & 0.76 \\
\hline C6 & $\mathrm{H}$ & M & VH & $\mathrm{L}$ & M & 0.6732 \\
\hline C7 & M & $\mathrm{H}$ & M & VH & M & 0.7132 \\
\hline C8 & $\mathrm{H}$ & M & $\mathrm{M}$ & $\mathrm{L}$ & M & 0.6 \\
\hline C9 & $\mathrm{H}$ & $\mathrm{H}$ & VH & $\mathrm{H}$ & VH & 0.8664 \\
\hline C10 & M & $\mathrm{H}$ & M & $\mathrm{H}$ & M & 0.68 \\
\hline C11 & $\mathrm{L}$ & $\mathrm{L}$ & M & $\mathrm{H}$ & M & 0.52 \\
\hline $\mathrm{C} 12$ & $\mathrm{~L}$ & $\mathrm{M}$ & $\mathrm{L}$ & $\mathrm{L}$ & M & 0.48 \\
\hline
\end{tabular}


In Fuzzy TOPSIS 1, the aggregation of the rating of alternatives and weight of each criterion is done by using Eq. (7) and (6) respectively. Similarly, in Fuzzy TOPSIS 2 the aggregation of the rating of the alternatives and weight of each criterion is done by using Eq. (15). The aggregated weight of each criterion from fuzzy TOPSIS 1 and the aggregated rating of the alternatives from fuzzy TOPSIS 2 is shown in Table 6 and 7 respectively.

Step 3: Construction of the normalized matrix

The normalization of the aggregated rating of the alternatives is done by using Eq. (8) for Fuzzy TOPSIS 1 and by using Eq. (16), (17) for fuzzy TOPSIS 2. The normalized aggregated rating for alternatives of Fuzzy TOPSIS 1 and 2 is shown in Table 8 and 9 respectively.

Table 7

Aggregated rating of the alternative in Fuzzy TOPSIS 2

\begin{tabular}{|c|c|c|c|c|c|c|c|c|c|c|c|c|}
\hline & C1 & C2 & C3 & C4 & C5 & C6 & C7 & C8 & C9 & C10 & C11 & $\mathrm{C} 12$ \\
\hline A1 & $(7,9.6,10)$ & $(5,7.8,10)$ & $(0,3.4,7)$ & $(0,2.2,5)$ & $(3,6.6,10)$ & $(1,5.4,10)$ & $(3,6.6,9)$ & $(1,3,5)$ & $(3,5,7)$ & $(1,3.8,7)$ & $(0,2.2,5)$ & $(0,0.8,3)$ \\
\hline A2 & $(3,7,10)$ & $(7,9,10)$ & $(7,9,10)$ & $(5,7,9)$ & $(3,5,7)$ & $(5,7,9)$ & $(5,7.4,10)$ & $(9,10,10)$ & $(3,5,7)$ & $(3,5,7)$ & $(3,5,7)$ & $(1,3,5)$ \\
\hline A3 & $(0,2.6,7)$ & $(0,2.6,7)$ & $(1,3.4,7)$ & $(0,2.2,7)$ & $(0,1,3)$ & $(0,1.8,5)$ & $(3,5.4,9)$ & $(3,5.8,10)$ & $(1,4.6,10)$ & $(1,4.2,7)$ & $(5,7.4,10)$ & $(1,3,5)$ \\
\hline A4 & $(7,9,10)$ & $(3,5.4,9)$ & $(7,9,10)$ & $(7,9,10)$ & $(7,9,10)$ & $(5,7,9)$ & $(0,2.6,5)$ & $(3,5,7)$ & $(5,7,9)$ & $(3,5,7)$ & $(0,1,3)$ & $(0,1,3)$ \\
\hline A5 & $(9,10,10)$ & $(1,4.2,9)$ & $(7,9,10)$ & $(7,9,10)$ & $(1,3,5)$ & $(5,7,9)$ & $(5,7,9)$ & $(7,9,10)$ & $(5,7,9)$ & $(3,5,7)$ & $(7,9,10)$ & $(7,9,10)$ \\
\hline A6 & $(5,7.4,10)$ & $(5,7,9)$ & $(7,9,10)$ & $(3,5,7)$ & $(1,3,5)$ & $(7,9,10)$ & $(1,3,5)$ & $(3,5,7)$ & $(3,5,7)$ & $(0,0.8,3)$ & $(3,5,7)$ & $(0,1,3)$ \\
\hline A7 & $(1,4.2,7)$ & $(1,4.2,7)$ & $(3,5,7)$ & $(3,7.4,10)$ & $(3,6.6,10)$ & $(1,5.4,9)$ & $(3,5.8,9)$ & $(7,9,10)$ & $(1,4.2,7)$ & $(0,1,3)$ & $(0,2.2,5)$ & $(0,2.2,5)$ \\
\hline A8 & $(1,3.8,7)$ & $(0,1.6,5)$ & $(0,2.2,5)$ & $(0,2.2,5)$ & $(3,6.2,9)$ & $(0,0.8,3)$ & $(0,2.2,5)$ & $(0,2.2,5)$ & $(7,9.4,10)$ & $(7,9.4,10)$ & $(1,3.8,7)$ & $(1,4.2,7)$ \\
\hline A9 & $(3,6.6,10)$ & $(1,4.2,7)$ & $(3,7.4,10)$ & $(0,3.4,7)$ & $(3,7.4,10)$ & $(0,2.2,5)$ & $(7,9,10)$ & $(1,3,5)$ & $(9,10,10)$ & $(9,10,10)$ & $(1,3,5)$ & $(0,1,3)$ \\
\hline
\end{tabular}

\section{Table 8}

Normalized Aggregated rating of alternative in Fuzzy TOPSIS 1

\begin{tabular}{cccccccccccccc}
\hline & C1 & C2 & C3 & C4 & C5 & C6 & C7 & C8 & C9 & C10 & C11 & C12 \\
\hline A1 & 0.511 & 0.419 & 0.188 & 0.123 & 0.354 & 0.289 & 0.358 & 0.206 & 0.271 & 0.206 & 0.123 & 0.053 \\
A2 & 0.294 & 0.372 & 0.372 & 0.295 & 0.211 & 0.295 & 0.311 & 0.415 & 0.211 & 0.211 & 0.211 & 0.127 \\
A3 & 0.191 & 0.191 & 0.240 & 0.163 & 0.083 & 0.134 & 0.381 & 0.407 & 0.322 & 0.297 & 0.520 & 0.212 \\
A4 & 0.399 & 0.244 & 0.399 & 0.399 & 0.399 & 0.289 & 0.119 & 0.226 & 0.316 & 0.226 & 0.053 & 0.053 \\
A5 & 0.376 & 0.160 & 0.337 & 0.337 & 0.115 & 0.267 & 0.267 & 0.337 & 0.267 & 0.191 & 0.337 & 0.337 \\
A6 & 0.378 & 0.359 & 0.453 & 0.257 & 0.154 & 0.453 & 0.154 & 0.257 & 0.257 & 0.050 & 0.257 & 0.060 \\
A7 & 0.230 & 0.230 & 0.274 & 0.400 & 0.358 & 0.296 & 0.318 & 0.484 & 0.272 & 0.064 & 0.124 & 0.124 \\
A8 & 0.236 & 0.106 & 0.141 & 0.141 & 0.385 & 0.060 & 0.141 & 0.141 & 0.500 & 0.573 & 0.236 & 0.261 \\
A9 & 0.300 & 0.193 & 0.335 & 0.159 & 0.335 & 0.104 & 0.405 & 0.138 & 0.451 & 0.451 & 0.138 & 0.054 \\
\hline
\end{tabular}

Table 9

Normalized Aggregated rating of alternative in Fuzzy TOPSIS 2

\begin{tabular}{lccccccccc}
\hline & $\mathbf{A 1}$ & $\mathbf{A 2}$ & $\mathbf{A 3}$ & $\mathbf{A 4}$ & $\mathbf{A 5}$ & $\mathbf{A 6}$ & $\mathbf{A 7}$ & $\mathbf{A 8}$ & A9 \\
\hline C1 & $(0.7,0.96,1)$ & $(0.3,0.7,1)$ & $(0,0.26,0.7)$ & $(0.7,0.9,1)$ & $(0.9,1,1)$ & $(0.5,0.74,1)$ & $(0.1,0.42,0.7$ & $(0.1,0.38,0.7$ & $(0.3,0.66,1)$ \\
C2 & $(0.5,0.78,1)$ & $(0.7,0.9,1)$ & $(0,0.26,0.7)$ & $(0.3,0.54,0.9$ & $(0.1,0.42,0.9$ & $(0.5,0.7,0.9$ & $(0.1,0.42,0.7$ & $(0,0.16,0.5)$ & $(0.1,0.42,0.7$ \\
C3 & $(0,0.34,0.7)$ & $(0.7,0.9,1)$ & $(0.1,0.34,0.7$ & $(0.7,0.9,1)$ & $(0.7,0.9,1)$ & $(0.7,0.9,1)$ & $(0.3,0.5,0.7)$ & $(0,0.22,0.5)$ & $(0.3,0.74,1)$ \\
C4 & $(0,0.22,0.5)$ & $(0.5,0.7,0.9$ & $(0,0.22,0.7)$ & $(0.7,0.9,1)$ & $(0.7,0.9,1)$ & $(0.3,0.5,0.7$ & $(0.3,0.74,1)$ & $(0,0.22,0.5)$ & $(0,0.34,0.7)$ \\
C5 & $(0.3,0.66,1)$ & $(0.3,0.5,0.7$ & $(0,0.1,0.3)$ & $(0.7,0.9,1)$ & $(0.1,0.3,0.5)$ & $(0.1,0.3,0.5$ & $(0.3,0.66,1)$ & $(0.3,0.62,0.9$ & $(0.3,0.74,1)$ \\
C6 & $(0.1,0.54,1)$ & $(0.5,0.7,0.9$ & $(0,0.18,0.5)$ & $(0.5,0.7,0.9)$ & $(0.5,0.7,0.9)$ & $(0.7,0.9,1)$ & $(0.1,0.54,0.9$ & $(0,0.08,0.3)$ & $(0,0.22,0.5)$ \\
C7 & $(0.3,0.66,0.9$ & $(0.5,0.74,1)$ & $(0.3,0.54,0.9$ & $(0,0.26,0.5)$ & $(0.5,0.7,0.9)$ & $(0.1,0.3,0.5$ & $(0.3,0.58,0.9$ & $(0,0.22,0.5)$ & $(0.7,0.9,1)$ \\
C8 & $(0.1,0.3,0.5)$ & $(0.9,1,1)$ & $(0.3,0.58,1)$ & $(0.3,0.5,0.7)$ & $(0.7,0.9,1)$ & $(.3,0.5,0.7)$ & $(0.7,0.9,1)$ & $(0,0.22,0.5)$ & $(0.1,0.3,0.5)$ \\
C9 & $(0.3,0.5,0.7)$ & $(0.3,0.5,0.7$ & $(0.1,0.46,1)$ & $(0.5,0.7,0.9)$ & $(0.5,0.7,0.9)$ & $(0.3,0.5,0.7$ & $(0.1,0.42,0.7$ & $(0.7,0.94,1)$ & $(0.9,1,1)$ \\
C1 & $(0.1,0.38,0.7$ & $(0.3,0.5,0.7$ & $(0.1,0.42,0.7$ & $(0.3,0.5,0.7)$ & $(0.3,0.5,0.7)$ & $(0,0.08,0.3)$ & $(0,0.1,0.3)$ & $(0.7,0.94,1)$ & $(0.9,1,1)$ \\
C1 & $(0,0.22,0.5)$ & $(0.3,0.5,0.7$ & $(0.5,0.74,1)$ & $(0,0.1,0.3)$ & $(0.7,0.9,1)$ & $(0.3,0.5,0.7$ & $(0,0.22,0.5)$ & $(0.1,0.38,0.7$ & $(0.1,0.3,0.5)$ \\
C1 & $(0,0.08,0.3)$ & $(0.1,0.3,0.5$ & $(0.1,0.3,0.5)$ & $(0,0.1,0.3)$ & $(0.7,0.9,1)$ & $(0,0.1,0.3)$ & $(0,0.22,0.5)$ & $(0.1,0.42,0.7$ & $(0,0.1,0.3)$ \\
\hline
\end{tabular}

\section{Step 4: Construction of the weighted normalized matrix and distance calculation}

The weighted normalized matrix for Fuzzy TOPSIS 1 and Fuzzy TOPSIS 2 are calculated. For Fuzzy TOPSIS $1 \& 2$, we consider all criteria as a benefit criteria. The PIS and NIS of each alternative in Fuzzy TOPSIS 1 are calculated according to the Eq. (10), (11), (12) and (13). For Fuzzy TOPSIS 2, we consider $v_{i}^{P}=(1,1,1)$ and $v_{i}^{N}=(0,0,0)$ and then calculate the distance. 
Step 5: Calculation of Closeness Co-efficient and ranking of the alternatives

The Closeness Co-efficient for the alternatives along with distance calculation and ranking of the alternatives of Fuzzy TOPSIS 1 and Fuzzy TOPSIS 2 method is shown in Table 10 and 11 respectively.

Table 10

Distance calculation and CC of the alternative in Fuzzy TOPSIS 1

\begin{tabular}{|c|c|c|c|c|}
\hline & $D^{P}$ & $D^{N}$ & $\mathrm{CC}$ & RANK \\
\hline A1 & 0.06376 & 0.058919 & 0.480269 & 2 \\
\hline A2 & 0.058955 & 0.053375 & 0.47516 & 3 \\
\hline A3 & 0.067528 & 0.051205 & 0.431265 & 9 \\
\hline A4 & 0.062765 & 0.055751 & 0.470409 & 4 \\
\hline A5 & 0.061928 & 0.048471 & 0.439053 & 7 \\
\hline A6 & 0.068283 & 0.055867 & 0.449996 & 6 \\
\hline A7 & 0.068087 & 0.052994 & 0.437675 & 8 \\
\hline A8 & 0.072577 & 0.062515 & 0.462758 & 5 \\
\hline A9 & 0.061691 & 0.058597 & 0.487141 & 1 \\
\hline
\end{tabular}

Table 11

Distance calculation and CC of the alternative in Fuzzy TOPSIS 2

\begin{tabular}{|c|c|c|c|c|}
\hline & $\bar{D}^{P}$ & $D^{N}$ & $\mathrm{CC}$ & RANK \\
\hline A1 & 8.18481587 & 5.84207902 & 0.416491252 & 5 \\
\hline A2 & 7.143575009 & 6.718115494 & 0.484653404 & 2 \\
\hline A3 & 8.717707188 & 5.375723201 & 0.381434686 & 7 \\
\hline A4 & 7.478130167 & 6.180545295 & 0.452499608 & 3 \\
\hline A5 & 6.790962797 & 7.176828664 & 0.513812701 & 1 \\
\hline A6 & 8.057979904 & 5.474792256 & 0.404558075 & 6 \\
\hline A7 & 8.598200352 & 5.29291125 & 0.381028632 & 8 \\
\hline A8 & 8.595257299 & 4.965898868 & 0.366185509 & 9 \\
\hline A9 & 7.629642707 & 6.167583141 & 0.447016176 & 4 \\
\hline
\end{tabular}

\section{Discussion and Managerial Implication}

The ranking of the alternatives, from the two-different aggregation method of Fuzzy TOPSIS, shown in Table 10 and 11 respectively are different from each other. From Fuzzy TOPSIS 1 method, we get $A 9>A 1>A 2>A 4>A 8>A 6>A 5>A 7>A 3$ and from Fuzzy TOPSIS 2, we get $A 5>A 2>$ $A 4>A 9>A 1>A 6>A 3>A 7>A 8$. In Fuzzy TOPSIS 1, method separate market for the new and remanufactured product, sustainable product design, proper business model and company policy are major success factor remanufacturing operations. On the other hand, in Fuzzy TOPSIS 2 method proper infrastructure and advanced remanufacturing technology, proper business model and company policy are the major success factor. Both the results are analysed by the expert team and they give more weightage on the result obtain from Fuzzy TOPSIS 2. The reason behind the better result for Fuzzy TOPSIS 2 is that in Fuzzy TOPSIS 1 defuzzification (GIM) process is done at the beginning i.e. before the aggregation of the individual expert opinion which results in loss of information. Proper infrastructure and advance remanufacturing technology signify the location of the remanufacturing facility, equipped with modern equipment and technology. As remanufacturing process encompasses with sub-operations such as disassembly, cleaning, inspection, testing and reassembly. Each of these sub-operations requires modern and advance technology. For example, crack detection during inspection and salvaging require advanced technology such as thermal spray, magnetic flux. Also, use of RFID technology in the product provides the information of the product quality. Proper business model and company policy refer to the what buyback schemes they have adopted to collect their used product, design of remanufacturable product, price of the remanufactured product etc. Separate market 
for the new and remanufactured product is another success factor for remanufacturing. If new and remanufactured product sells in the same market, then it may hamper the sale of the new product or it can cannibalize the market of the new product. Other success factors such as sustainable product design, support form top management, encourage customers to buy more remanufactured product are also important from remanufacturing point-of-view.

Price sensitive market and low labour cost make remanufacturing a viable business proposition in India. But lack of proper legislative law, customers negative attitude, resource scarcity, lack of proper business model of the company for remanufacturing are the common barriers in India. This study shows the common barriers in remanufacturing and also illustrate the success factors and prioritized them by the industry expert. This study also helps the other OEM to initiate remanufacturing business in India.

\section{Conclusion}

The reduction of natural resources and global environmental consciousness are essentially compelling various industrial sectors to elect some alternative technologies, which possibly help in the extention of the useful life of a product. Product recovery operations have already been accepted globally as one of the most appropriate propositions in this quest. The contribution of this paper lies prioritization of the success factor of remanufacturing business in the Indian context. The methodology adopted in this paper for prioritization of critical success factors in remanufacturing shows quite satisfactory results. The company too agreed upon the test results. Also, the efficiency of two Fuzzy TOPSIS method is compared in this study.

The result of this paper is based on a particular case study of a specific company and the opinions are based on subjective decisions made by the experts of the company. More case studies may be incorporated in this paper for reliable outcomes. Also, Fuzzy Analytic Hierarchy Process can be used to calculate the weights of the criteria.

\section{References}

Abdulrahman, M. D. A., Subramanian, N., Liu, C., \& Shu, C. (2015). Viability of remanufacturing practice: a strategic decision making framework for Chinese auto-parts companies. Journal of Cleaner Production, 105, 311-323.

Bhanot, N., Rao, P.V., \& Deshmukh, S.G. (2017). An Integrated approach for analysing the enablers and barriers of sustainable manufacturing. Journal of Cleaner Production, 142, 4412-4439.

Biswas, W., \& Rosano, M. (2011). A life cycle greenhouse gas assessment of remanufactured refrigeration and air conditioning compressors. International Journal of Sustainable Manufacturing, 2(2-3), 222-236.

Bufardi, A., Gheorghe, R., Kiritsis, D., \& Xirouchakis, P. (2004). Multicriteria decision-aid approach for product end-of-life alternative selection. International Journal of Production Research, 42(16), 3139-3157.

Chan, J. W. (2008). Product end-of-life options selection: grey relational analysis approach. International Journal of Production Research, 46(11), 2889-2912.

Du, Y., \& Li, C. (2014). Implementing energy-saving and environmental-benign paradigm: machine tool remanufacturing by OEMs in China. Journal of Cleaner Production, 66, 272-279.

Fang, H. C., Ong, S. K., \& Nee, A. Y. C. (2014). Product remanufacturability assessment based on design information. Procedia CIRP, 15, 195-200.

Feng, Y.T., Tian, Y.H., \& Zhu, Q. H. (2016). A combined input-output/decision making trial and evaluation laboratory method for evaluating effect of the remanufacturing sector development. Journal of Cleaner Production, 114, 103-113.

Ghazalli, Z., \& Murata, A. (2011). Development of an AHP-CBR evaluation system for remanufacturing: end-of-life selection strategy. International Journal of Sustainable Engineering, $4,2-15$. 
Golinska, P., Kosacka, M., Mierzwiak, R., \& Lewandowska, K. W. (2015). Grey Decision Making as a tool for classification of the sustainability level of remanufacturing company. Journal of Cleaner Production, 105, 28-40.

Govindan, K., Shankar, K.M., \& Kannan, D. (2016). Application of fuzzy analytic network process for barrier evaluation in automotive parts remanufacturing towards cleaner production-a study in an Indian scenario. Journal of Cleaner Production, 114, 199-213.

Ijomah, L. W., McMohan, A. C., Hammond, G.P., \& Newman, S.T. (2007). Development of design for remanufacturing guidelines to support sustainable manufacturing. Robotics and ComputerIntegrated Manufacturing, 23(6), 712-719.

Jiang, Z., Zhang, H., \& Sutherland, J.W. (2011). Development of multi-criteria decision making model for remanufacturing technology in portfolio selection. Journal of Cleaner production, 19, 19391945.

Mukherjee, K., \& Mondal, S. (2009). Analysis of issues relating to remanufacturing technology-a case of an Indian company. Technology Analysis \& Strategic Management, 21(5), 639-652.

Prakash, C., \& Barua, M.K. (2015). Integration of AHP-TOPSIS method for prioritizing the solutions of reverse logistics adoption to overcome its barriers under fuzzy environment. Journal of Manufacturing Systems, 37, 599-615.

Rao, R. V., \& Padmanabhan, K.K. (2010). Selection of best product end-of-life scenario using digraph and matrix methods. Journal of Engineering Design, 21, 455-472.

Rathore, P., Kota, S., \& Chakrabarti, A. (2011). Sustainability through remanufacturing in India: a case study on mobile handsets. Journal of Cleaner Production, 19, 1709-1722.

Ravi, V. (2015). Analysis of interactions among barriers of eco-efficiency in electronics packaging industry. Journal of Cleaner Production, 101, 16-25.

Saavedra, M.B.Y, Barquet, P.B.A, Rozenfeld, H., Forcellini, F., \& Ometto, A.R. (2013). Remanufacturing in Brazil: case studies on the automotive sector. Journal of Cleaner production, 53, 267-276.

Sabharwal, S., \& Garg, S. (2013). Determining cost effectiveness index of remanufacturing: A graph theoretic approach. International Journal of Production Economics, 144, 521-532.

Shaharudin, M. R., Zailani, S., \& Tan, K.C. (2015). Barriers to product returns and recovery management in a developing country: investigation using multiple methods. Journal of Cleaner Production, 96, 220-232.

Sharma, V., Garg, S.K., \& Sharma, P.B. (2014). Identification of major drivers and roadblocks for remanufacturing in India. Journal of Cleaner Production, 112(3), 1882-1892.

Subramanian, N., Gunasekaran, A., Abdulrahman, M., \& Liu, C. (2014). Factors for implementing endof-life product reverse logistics in the Chinese manufacturing sector. International Journal of Sustainable Development \& World Ecology, 21, 235-245.

Thierry, M., Salomon, M., Van Nunen, J., \& Van Wassenhove, L. (1995). Strategic issues in product recovery management. California Management Review, 37(2), 114-135.

Tian, G., Chu, J., Hu, H., \& Li, H. (2014). Technology innovation system and its integrated structure for automotive components remanufacturing industry development in China. Journal of Cleaner Production, 85, 419-432.

Wang, Y., Chang, X., Chen, Z., Zhong, Y., \& Fan, T. (2014). Impact of subsidy policies on recycling and remanufacturing using system dynamics methodology: a case of auto parts in China. Journal of Cleaner Production, 74, 161-171.

Xia, X., Govindan, K., \& Zhu, Q. (2015). Analysing internal barriers for automotive parts remanufacturers in China using grey-DEMATEL approach. Journal of Cleaner Production, 87, 811825.

Xiang, W., \& Ming, C. (2011). Implementing extended producer responsibility: vehicle remanufacturing in China. Journal of Cleaner Production, 19(6), 680-686.

Yusop, N.M., Wahab, D.A., \& Saibani, N. (2016). Realising the automotive remanufacturing roadmap in Malaysia: challenges and the way forward. Journal of Cleaner Production, 112(3), 1910-1919 
Zhu, Q., Sarkis, J., \& Lai, K.H. (2015). Reprint of Supply chain-based barriers for truck-engine remanufacturing in China. Transportation Research Part E: Logistics and Transportation Review, 74, 94-108.

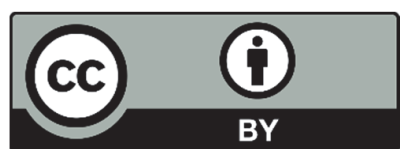

(C) 2017 by the authors; licensee Growing Science, Canada. This is an open access article distributed under the terms and conditions of the Creative Commons Attribution (CC-BY) license (http://creativecommons.org/licenses/by/4.0/). 